\title{
Perthes syndrome: a pediatric case
}

\author{
Fatma Fitouri, Sondes Sahli, Yasmine Houas, Nizar Sassi, Mourad Hamzaoui \\ Pediatric Surgery Department “A”, Children Hospital, Tunis; Manar University Tunis, Tunisia
}

\begin{abstract}
The traumatic asphyxia or Perthes syndrome is uncommon. It is a clinical syndrome associating an ecchymotic mask consisting of cervicofacial cyanosis, petechiae and subconjunctival hemorrhage to neurological and ocular symptoms. The authors report a pediatric case of 8-year-old boy who was a highway accident victim. He presented a cervicofacial cyanosis, petechiae and immediate massive bilateral sub-conjunctival hemorrhage. The attitude was limited to a clinical monitoring. The decline is twelve months.
\end{abstract}

Key words: Perthe's syndrome, cervicofacial cyanosis, hemorrhage, children

Acta Angiol 2017; 23, 4: 163-164

\section{Introduction}

Described for the first time in 1837 by Ollivier, the traumatic asphyxia or Perthes syndrome is uncommon. It is a clinical syndrome associating anecchymotic mask consisting of cervicofacial cyanosis, petechiae and subconjunctival hemorrhage to neurological and ocular symptoms. It follows asudden, severe and transient compression of the chest and/or the upper part of the abdomen, generally after road traffic accidents [I-4].
The physiopathology producing the classic findings in traumatic asphyxia involves a marked increase in thoracic pressure transmitted through the valveless superior vena cava and veins of the head and neck. A Valsalva maneuver as part of a pre-impact fear response may help to produce the marked venous pressure, reversal of venous flow, and capillary rupture, which result in the distinctive physical signs [1-4]. The treatment includes rapid chest decompression andcardiopulmonary resuscitation. The prognosis is
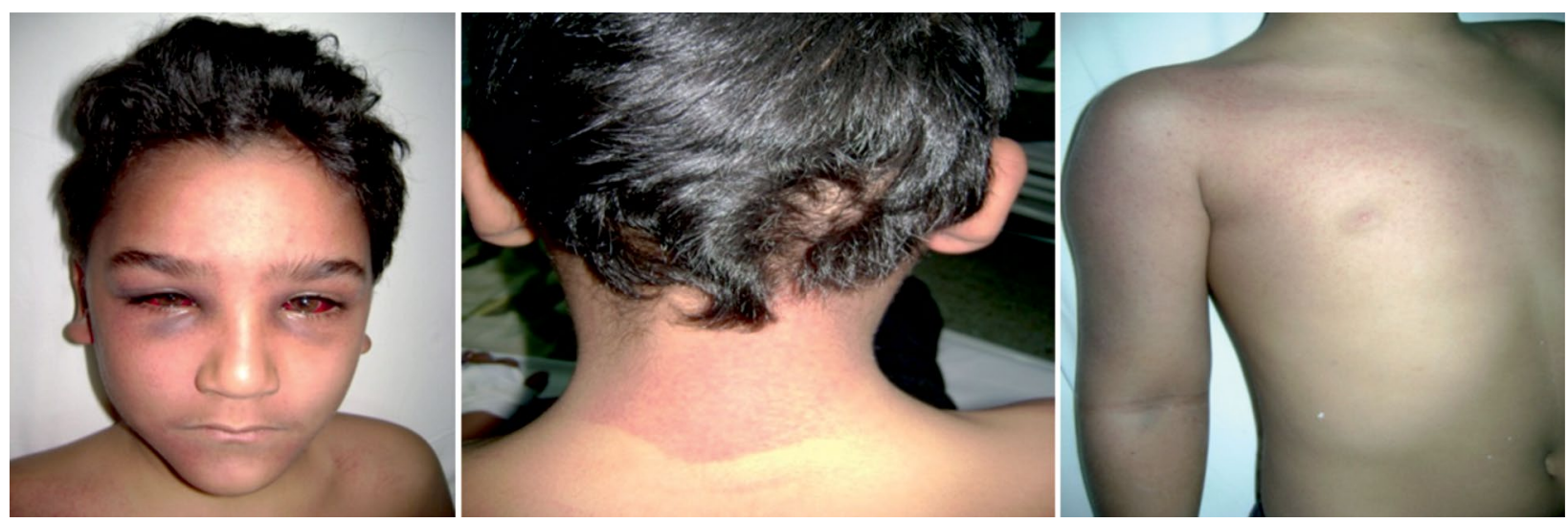

Figure I. Cervicofacial and thoracic cyanosis and petechiae

Address for correspondence: Fatma Fitouri, Pediatric Surgery Department “A”, Children Hospital, Tunis; Manar University Tunis, Tunisia, e-mail: fitfatma@yahoo.fr 


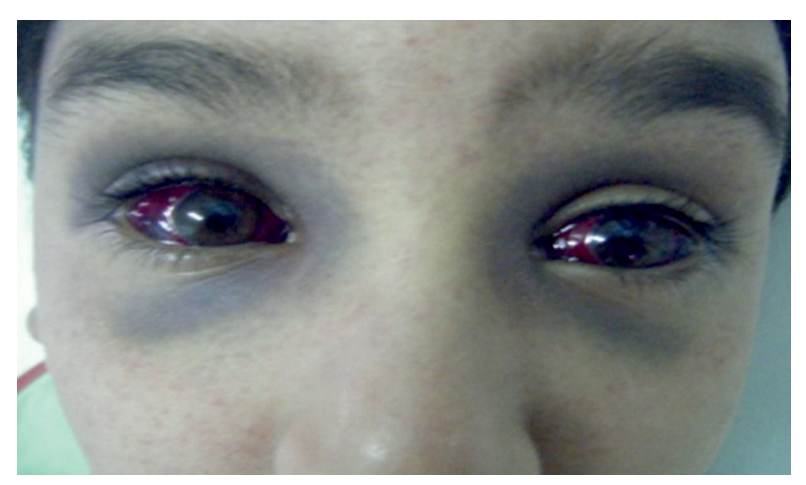

Figure 2. Bilateral sub-conjunctival hemorrhage

good but a prolonged thoracic compression could lead to cerebral anoxia and neurologicalsequelae. The outcome of associated visual impairment is difficult to predict, but permanent impairment is usually associated with retinal hemorrhage and involvement of the macula or optic disc [4].

\section{Case study}

An 8-year-old boy, without medical history, was a highway accident victim. The child was a pedestrian struck by a car with an abdominal and thoracic impactand a fall with an occipital reception and an initial loss of consciousness. The neurological, hemodynamic and respiratory status was good. There were cervicofacial cyanosis and petechiae and immediate massive bilateral sub-conjunctival hemorrhage. The abdominal palpation and abdominal ultrasound were normal. There were no abnormalities at the ophthalmologic examination, especially there were no visual disturbances. The cerebral scan was normal. The hemoglobin level was stable. The attitude was limited to a clinical monitoring. The evolution was marked by the onset of a transient diplopia. The sub-conjunctival hemorrhage and purpura were regressed gradually. The decline was twelve months.

\section{Conclusions}

Perthes syndrome should be advocated in the face of an ecchymotic mask. The treatment is symptomatic. The prognosis is usually favourable, but if the compression was prolonged, true asphyxia, cerebral anoxia and neurological sequelae can accute.

\section{References}

I. Cuttaree H, Meyer P, Ertrand D, et al. Le syndrome d'asphyxie traumatique chez l'enfant. A propos de trois cas. Journal Européen des Urgences. 1993; 6: 106-110.

2. Barakat M, Belkhadir ZH, Belkrezia R, et al. Syndrome d'asphyxie traumatique ou syndrome de Perthes. À propos de six cas. Annales Françaises d'Anesthésie et de Réanimation. 2004; 23(I): 59-62, doi: 10.1016/j.annfar.2003.10.011.

3. Amraoui WE, Koraichi $A E$, Bentalha $A$, et al. Syndrome de Perthes secondaire à une crise d'asthme : à propos d'un cas chez un enfant de 15 ans. Revue de Pneumologie Clinique. 2016; 72(6): 359-362, doi: 10.1016/j.pneumo.2016.08.002.

4. Purdy R, Cogbill T, Landercasper J, et al. Temporary temporary blindness associated with traumatic asphyxia. The Journal of Emergency Medicine. 1988; 6(5): 373-376, doi: 10.1016/07364679(88)90008-x. 